\title{
REVIEW
}

\section{Rhizosphere immunity: targeting the underground for sustainable plant health management}

\author{
Zhong WEI ${ }^{1}$, Ville-Petri FRIMAN ${ }^{1,2}$, Thomas POMMIER ${ }^{1,3}$, Stefan GEISEN ${ }^{1,4}$, Alexandre JOUSSET $(\bowtie)^{1,5}$, \\ Qirong SHEN (凶) $)^{1}$
}

1 Key Laboratory of Plant Immunity, Jiangsu Key Laboratory for Organic Solid Waste Utilization, National Engineering Research Center for Organic-Based Fertilizers, Nanjing Agricultural University, Nanjing 210095, China 2 Department of Biology, University of York, York, YO10 5DD, UK

3 Ecologie Microbienne, UMR1418, French National Institute for Agricultural Research (INRA), University Lyon I, F-69622 Villeurbanne, France

4 Laboratory of Nematology, Wageningen University and Research, 6700ES Wageningen, the Netherlands 5 Institute of Environmental Biology, Ecology and Biodiversity, Utrecht University, 3584CH Utrecht, the Netherlands

\begin{abstract}
Managing plant health is a great challenge for modern food production and is further complicated by the lack of common ground between the many disciplines involved in disease control. Here we present the concept of rhizosphere immunity, in which plant health is considered as an ecosystem level property emerging from networks of interactions between plants, microbiota and the surrounding soil matrix. These interactions can potentially extend the innate plant immune system to a point where the rhizosphere immunity can fulfil all four core functions of a full immune system: pathogen prevention, recognition, response and homeostasis. We suggest that considering plant health from a meta-organism perspective will help in developing multidisciplinary pathogen management strategies that focus on steering the whole plant-microbe-soil networks instead of individual components. This might be achieved by bringing together the latest discoveries in phytopathology, microbiome research, soil science and agronomy to pave the way toward more sustainable and productive agriculture.
\end{abstract}

Keywords rhizosphere, soil microbiome, plant immunity, microbial ecology, plant health, soilborne pathogens

\section{Introduction}

Plant pathogens can destroy up to $30 \%$ of global agricultural outputs ${ }^{[1]}$ and hence there is an urgent need to develop disease-resistant cropping systems. Plants have

Received February 16, 2020; accepted April 25, 2020

Correspondences: A.L.C.Jousset@uu.nl, shenqirong@njau.edu.cn evolved several physiological adaptations that can provide immunity to some of these threats ${ }^{[2]}$. Plant defense mechanisms against diseases have long been considered in the context of plant immunity in an analogous fashion to human medicine ${ }^{[3]}$. However, this comparison is only valid to a certain extent and can be misleading because plants lack several characteristics associated with a fully adaptive immune system ${ }^{[4]}$. One of the limitations of plant defenses is the absence of an acquired immunity that can prevent reinfection by pathogens ${ }^{[5]}$. As a result, improving disease management by focusing on plant immunity offers limited prospects as innate resistance genes must be tediously built into the genome via breeding, while pathogens can easily overcome the resistance due to their relatively rapid rate of evolution. Alternative approaches to complement the missing plant immune functions via genetic engineering ${ }^{[6]}$ or by using large amounts of pesticides are problematic due to restrictive legal framework, limited public acceptance and in the case of pesticides adverse effects on the environment ${ }^{[7,8]}$. Furthermore, current high-yielding agricultural strategies are inherently unstable in the long-term, as they are highly dependent on heavy external agrochemicals inputs and require a strict control of unpredictable environmental parameters ${ }^{[9,10]}$. One solution to improve plant disease management is to shift away from the reductionist view in which plant health is studied by focusing on individual components in isolation, to a more holistic framework in which plant immunity is considered to emerge as a result of interactions with plant-associated microorganisms and environmental conditions ${ }^{[11]}$.

Plant immunity is typically viewed as a plant-centered process in which traits encoded by the plant genome determine resistance to pathogens. This concept has to some extent been softened by the disease triangle concept 
in which the environment is also considered to modulate plant susceptibility to diseases. The plant-centered view has been further challenged by growing evidence for the key role of microbes in plant health and disease resistance. Because plants are never sterile, their physiology, development and immunity are deeply intertwined with associated microorganisms up to the point where they might become dysfunctional without appropriate microbial partners ${ }^{[12]}$. Plants thus actively engineer their local environment, creating specific niches in their roots that are distinct from the surrounding soil matrix and often attractive for microbial growth.

Here, we pay special attention to the rhizosphere, the underground part of the plant consisting of the endorhizosphere, rhizoplane and ectorhizosphere ${ }^{[13]}$, as the key target for an integrative management of plant immunity. The rhizosphere is one of the key interfaces between plants and their environment, thanks to its large area, biological activity and interplay with the surrounding environment $^{[14-16]}$. We collect evidence from different disciplines to support this concept which is analogous to mucosal immunity in animals ${ }^{[17]}$. We highlight the components that form the rhizosphere, how they can be combined into a single integrated concept of rhizosphere immunity and give examples of how microbial interactions can extend innate plant immunity to cover all properties of full adaptive immunity. Finally, we pinpoint the usefulness of this concept for plant health at the practical level via the promotion of interdisciplinary collaboration and integration of different technologies into an innovative, multipletarget plant protection strategy.

\section{Rhizosphere immunity: plant health at the interface between plant, soil and microbiome}

Hidden belowground, the rhizosphere can be seen as the powerhouse of the plant immune system where plants, microorganisms and soil together form a tightly connected network that has an essential role in preventing pathogen attack (Fig. 1(a)). The rhizosphere has long served as a target for interventions by highly active yet often disjointed research fields including phytopathology, soil science and microbiology. As a result, intervention strategies have typically been employed independently, which may partly explain their limited impact. We propose that instead of focusing on individual components of the rhizosphere, intervention strategies should target the whole network formed by the plant, microbiota and the soil they inhabit. The rhizosphere contains a vast pool of functional characteristics that are involved in pathogen control, with each compartment showing some analogy with the mammalian immune system. We have divided these into three key components, namely plant-encoded, microbeencoded and soil-determined traits, and next characterize and consider their interactions in the context of rhizosphere immunity.

\subsection{Single component-encoded traits}

\subsubsection{Plant-encoded traits}

The plant genome encodes several traits that together form an intricate innate immune system allowing plants to detect and fight against pathogens ${ }^{[18-20]}$ (Fig. 1(b)). Plantencoded immune functions are based on the recognition of conserved microbe-associated molecular patterns (MAMPs) that detect pathogens by binding to specific receptors $^{[21,22]}$. These receptors activate defense responses on recognition of MAMPs that limit or prevent the proliferation of pathogens on or within the plant ${ }^{[21,22]}$. Pathogens, in turn, have evolved to produce and secrete effector proteins that interfere with either the recognition of MAMPs or the subsequent MAMP-triggered immune responses, leading to a coevolutionary arms race with their plant host ${ }^{[23,24]}$. Plant resistance genes can confer quantitative or complete resistance to diseases ${ }^{[25]}$ which
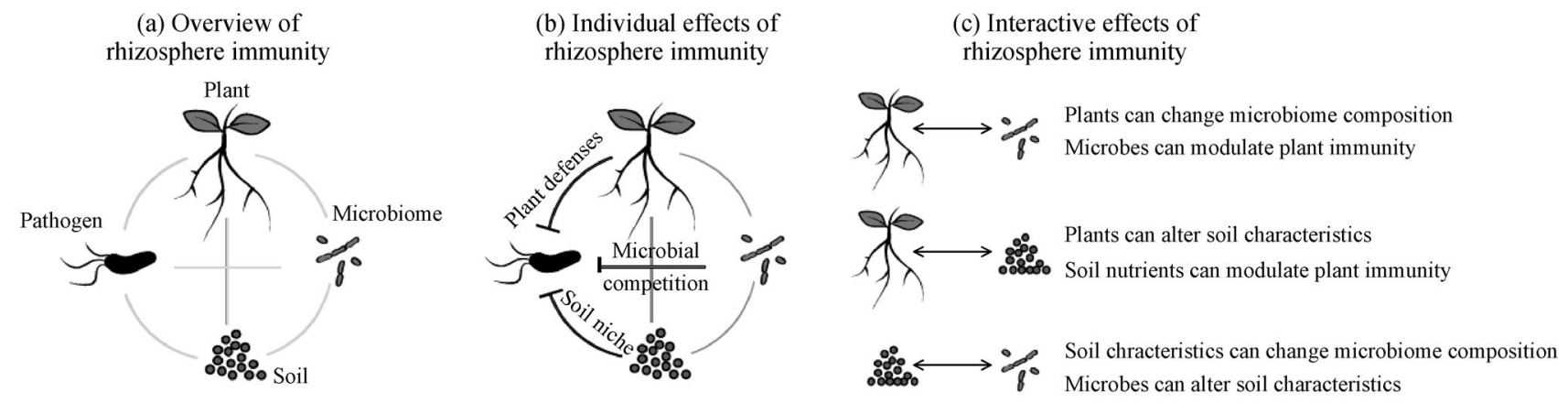

Fig. 1 Overview of the components of the rhizosphere immunity. (a) The rhizosphere can be considered to be a meta-organism encompassing interactions between the plant, microbiome, pathogen and the surrounding soil matrix. Each of these components can exert independent (b) and interactive effects on plant health (c), making rhizosphere immunity an emerging property of the whole agricultural ecosystem. 
also depends on the virulence of the pathogen. As a result, the genetic compatibility between the plant and the pathogen together determines whether a disease will develop. Although it has been shown that certain microbial pathogens can increase their infectivity during a single lifecycle by horizontal gene transfer ${ }^{[26]}$, plants are less flexible and their resistance is more limited by the genetic material that they have inherited. Moreover, while plants can respond to infections by systemically enhancing their immune defense, they do not have immunological memory that would help their immune system to specifically recognize of previously encountered pathogens. Unlike most animals ${ }^{[27]}$, archaea and bacteria ${ }^{[28]}$, acquiring immunity to a new pathogen for plants requires a mutation and selection process that stretches over many generations. Resistance genes can be combined and introduced to new varieties through plant breeding but this is a relatively slow and tedious process and ultimately can be overcome by rapidly evolving pathogens.

\subsubsection{Microbiome-encoded traits}

Rhizosphere microorganisms form a dense biofilm around plant roots ${ }^{[29]}$ and can contribute to disease suppression in multiple ways $^{[30]}$ (Fig. 1(b)). Thanks to its vast diversity, the microbiome offers a substantial functional gene pool that supersedes the number of genes present in the plant genome by orders of magnitude. Furthermore, the microbiome shows a certain level of self-organization and stability ${ }^{[31]}$ that can directly benefit the host, for example by promoting homeostasis ${ }^{[32]}$. Due to niche speciation, microbial species can coexist together in the rhizosphere by occupying subsets of root space and consuming distinct sets of plant- and soil-derived resources. As a result, highly diverse microbial communities likely leave only a few niches unoccupied and available for potential invading pathogen ${ }^{[33,34]}$. Moreover, as a side effect of the ongoing chemical interactions associated with microbial competition, several species produce inhibitory compounds that may restrict pathogen growth and virulence ${ }^{[35,36]}$. As a consequence, root-associated microbes have the potential to provide plants extended immunity by antagonizing pathogens $^{[33,36,37]}$.

\subsubsection{Soil-determined characteristics}

Plant roots 'bioengineer' the soil matrix in their vicinity

into a very different environment from the surrounding 'bulk' soil to the point that this difference could, in our opinion, be considered to form an individual component of the rhizosphere immunity (Fig. 1(b)). Moreover, the physicochemical properties of the soil can have deep legacy effects on the rhizosphere properties affecting pathogen suppression over multiple plant generations. For example, soil structure can constrain the ability of a pathogen to move toward its host plant and gain access to available nutrients, while soil $\mathrm{pH}$ can constrain pathogen growth, and soil particles adsorb and immobilize pathogens or their toxins ${ }^{[38-40]}$. Soil porosity and structure might further affect local pools of biodiversity and water flow ${ }^{[41]}$, which could either constrain or promote the passive movement of pathogens ${ }^{[42]}$. Altering soil physicochemical properties by using different amendments is an established strategy to manage soil fertility ${ }^{[43]}$. However, it is still often a process of trial and error with considerable uncertainties as to how to match the input with the expected and predicted responses.

\subsection{Interactions between different components}

All the above components contribute to disease suppression on their own. However, all the individual components are also intimately interlinked with each other and might interactively provide more substantial effects on pathogen suppression. Below we give an overview of some representative interactions between these components and their expected effects on rhizosphere immunity (Fig. 1(c)).

\subsubsection{Plant-microbiome interactions}

Plants recruit microorganisms, for example by secreting root exudates consisting of a blend of nutrients and bioactive compounds ${ }^{[4-46]}$ (Fig. 1(c)). These selected microorganisms will, in turn, interact with plant physiology and can modulate plant immune responses to pathogens $^{[47]}$.

\subsubsection{Plant-soil interactions}

Soil nutrient availability plays an important role in triggering plant defenses (Fig. 1(c)). The availability of key elements such as phosphorus, iron or calcium can therefore directly affect plant investment in pathogen defenses ${ }^{[48-50]}$. In return, plants affect soil elemental composition by taking up nutrients and adding carbon in the form of exudates and dead plant material, further shaping interactions between pathogen and microbiota ${ }^{[50]}$.

\subsubsection{Soil-microbiome interactions}

Soil structure and nutrient content are two major determinants of microbial community assembly ${ }^{[51-53]}$ (Fig. 1(c)), which determines the composition and functioning of microbiomes, including their ability to suppress pathogens ${ }^{[54,55]}$. The interactions between soil and microorganisms are bidirectional, with microbial communities further changing the soil structure and nutrient content by degrading organic matter, producing 
molecules binding soil particles together ${ }^{[56,57]}$ or chelating available nutrients ${ }^{[58]}$.

\section{Rhizosphere immunity: an immunity sensu stricto}

A major limitation of plant immunity is the lack of adaptive immunity. In contrast to animals or even bacteria, plants do not have immunological memory that would allow them to recognize and trigger a robust secondary response against a previously encountered pathogen ${ }^{[5]}$. Resistance must thus be predetermined by their genome, making their immunity inflexible. In contrast, the whole rhizosphere can together form an extended immunity that can be considered to have all the features of fully developed, adaptive immunity. We describe below how these characteristics match the four key medical characteristics of an immunity sensu stricto: prevention, detection, response and homeostasis ${ }^{[59]}$ (Fig. 2).

\subsection{Prevention}

As the root system offers natural openings for plant pathogen entry, one of the primary functions of the rhizosphere immune system is to prevent pathogens from getting inside the plant. The rhizosphere forms a constitutive physical barrier against most pathogens comparable to mammalian mucosa. This barrier function is in part provided by the soil structure via various physicochemical mechanisms discussed above ${ }^{[38-40]}$. Also the plant itself forms a physical barrier against the pathogen through the chemical reinforcement of the root surface with suberin and lignin layers ${ }^{[60-62]}$, while microorganisms contribute to disease prevention by competing for the physical space and nutrients on root surfaces, which often triggers the production of toxic compounds that can further repel the pathogen. Finally, this microbial activity can be further stimulated by the plant through the production and excretion of polysaccharides that induce bacterial biofilm formation ${ }^{[63]}$.

\subsection{Detection}

If a pathogen can overcome the physical and microbiomemediated competition and start multiplying in the rhizosphere, it may be still be detected and suppressed. Pathogen detection can occur at various levels. Plants can recognize MAMPs such as surface molecules or effectors $^{[21,22]}$, or respond to damage resulting from early infections ${ }^{[64,65]}$. Alternatively, the microbiome can also 'detect' pathogens by responding to their presence. For example, certain pathogen virulence traits such as fusaric acid production in Fusarium spp. can affect interactions with other microorganisms ${ }^{[66-68]}$ while soil acidification caused by Rhizoctonia solani triggers changes in microbiome composition and activity ${ }^{[69]}$. The presence of the pathogen can also promote the reproduction of natural enemies such as viruses ${ }^{[70]}$, predatory bacteria ${ }^{[71]}$, and protists $^{[72]}$, potentially triggering cascades in microbial trophic networks, which could feed back in the activation of plant immune responses.

\subsection{Response}

Pathogen presence can trigger a range of responses that will inhibit its further growth. Plant responses include apoptosis ${ }^{[62,73]}$ and the production of defense compounds such as callose ${ }^{[74]}$. At the microbiome level, molecular cues produced by the pathogen or changes in the environmental conditions can lead to enhanced expression of antagonistic traits such as increased production of antibiotics $^{[69]}$. The accumulation of other microbial antagonists such as bacteriophages may also hamper future pathogen growth. Together, the response will reduce pathogen densities, or potentially impose selection that

\begin{tabular}{|c|c|c|c|c|}
\hline & Prevention & Detection & Response & Homeostasis \\
\hline & $\begin{array}{l}\text { The production } \\
\text { of suberin and } \\
\text { antimicrobials }\end{array}$ & $\begin{array}{l}\text { MAMPs } \\
\text { Tissue damage }\end{array}$ & $\begin{array}{l}\text { Hypersensitive response } \\
\text { and necrosis, production } \\
\text { of antimicrobials and } \\
\text { callus deposition }\end{array}$ & $\begin{array}{l}\text { Root growth and } \\
\text { development and } \\
\text { chelation of iron }\end{array}$ \\
\hline 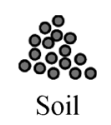 & $\begin{array}{l}\text { Soil } \mathrm{pH} \text { and } \\
\text { porosity }\end{array}$ & & & $\begin{array}{l}\text { Sorption and inactiva } \\
\text { of pathogens and } \\
\text { their toxins }\end{array}$ \\
\hline & $\begin{array}{l}\text { Niche preemption } \\
\text { and competition }\end{array}$ & $\begin{array}{l}\text { Resource limitation } \\
\text { Microbe-microbe- } \\
\text { plant cell signaling }\end{array}$ & $\begin{array}{l}\text { Antibiosis, resource } \\
\text { competition, predation } \\
\text { and parasitism }\end{array}$ & $\begin{array}{l}\text { Degradation of waste } \\
\text { and toxic compounds } \\
\text { Chelation of iron }\end{array}$ \\
\hline
\end{tabular}

Fig. 2 Mechanistic contributions of the rhizosphere components (plant, soil and microbiome) to the key functions associated with immunity of the rhizosphere system. In reference to the medical definition of immunity, these traits are classified into pathogen prevention, pathogen detection, response to pathogen presence and rhizosphere homeostasis. 
leads to evolutionary trade-offs where increased resistance to antagonists comes with a cost of reduced virulence ${ }^{[75]}$. If antagonists become dormant after pathogen eradication (e.g., by forming spores) they may form a defensive reservoir that can be rapidly reactivated upon reinfection providing an acquired immunological memory to the rhizosphere.

\subsection{Homeostasis}

In addition to pathogen detection and eradication, homeostasis in the face of abiotic and biotic stresses is an essential function of plant health. The rhizosphere immune system degrades senescent or dying biological cells (from roots or microbes) and pollutants and agrochemical residues that can have negative impacts on plants. Accumulation of toxic compounds in the rhizosphere, such as virulence factors released by pathogens during infection, can also have harmful impacts on plant physiology, alter microbial community structure and functioning, or compromise the ability of the soil to retain nutrients ${ }^{[76]}$. Each rhizosphere component contributes to homeostasis. The plant supplies carbon to the microbiome that can, due to its enzymatic arsenal, detoxify or degrade phytotoxic compounds, mycotoxins and pollutants ${ }^{[77,78]}$, while plant compounds and cells form a protective barrier that prevents the entry of toxins. Finally, the soil itself can contribute to homeostasis through the inactivation and adsorption of pollutants and phytotoxic compounds to clays or humic acids ${ }^{[79,80]}$.

\section{Rhizosphere immunity in the context of plant pathogen infections}

We will next discuss how rhizosphere immunity is linked with the emergence of plant diseases and discuss several ways it could guide in the development of rhizosphere management. We argue that when only the plant (Fig. 3(a), see 2.1.1) or the soil matrix components are considered, rhizosphere immunity is mainly constitutive and incapable of changing dynamically in response to infections. However, when microbiome component is included, rhizosphere immunity can also be viewed as an adaptive system in which immunological memory is provided by pathogen-suppressive microbes than can constrain reinfecting pathogens within and between plant generations.

\subsection{Constitutive soil suppressiveness}

Plant and soil microbiologists worldwide have reported that some soils naturally protect plants from pathogens. This effect may be attributed to two underlying mechanisms which we categorize here under the 'constitutive soil suppressiveness' concept (Fig. 3(b)). First, some soils might not simply offer a suitable physico-chemical environment, e.g., the right $\mathrm{pH}$ or nutrients, for pathogen survival. However, soil suppressiveness driven by extreme abiotic conditions (low $\mathrm{pH}$ or poor nutrient availability) will likely be bad also for plant growth either directly or by suppressing plant growth-promoting microbes. As a result, manipulations aiming to relieve stress caused by abiotic growth conditions might also reduce soil suppressiveness. Alternatively, soil suppressiveness could be due to the properties of the microbial community that may prevent the growth of pathogens (often classified as general soil suppressiveness ${ }^{[81]}$ ). Although the exact nature of suppressive microbiomes is still debated, suppressive soils often have a high prevalence of antimicrobial genes ${ }^{[54]}$ or are overrepresented by microbes that can efficiently compete with the pathogen for soil- and root-associated niches ${ }^{[33]}$. Soil suppressiveness can occur naturally ${ }^{[54]}$ or be induced by cropping regime ${ }^{[82]}$, soil organic amendments $^{[83]}$ or microbial inoculants ${ }^{[36]}$. While microbiomemediated suppressiveness can become dynamic (see 4.2), it is ephemeral and often quickly lost or disrupted due to unfavorable soil physicochemical properties or by improper agricultural management ${ }^{[84]}$.

\subsection{Acquired rhizosphere immunity}

The established definition of plant immunity composed of well-described salicylic acid-mediated systemic acquired resistance ${ }^{[85]}$ and the jasmonate-dependent induced systemic resistance ${ }^{[86,87]}$ can change considerably when placed in a rhizosphere microbiome context. This extended microbiome-mediated effect on innate plant immunity has been described as a "cry for help"[86]. In addition to directly repelling pathogens via the production of pathogen-suppressing compounds ${ }^{[86]}$, some exudates can be used to recruit and activate plant-beneficial microbes ${ }^{[88,89]}$ (Fig. 3(c)). For example, plants can secrete certain compounds that increase the relative abundance of antagonistic species, activate the expression of antimicrobial traits of existing microbiota, or favor microorganisms capable of directly stimulating plant immunity ${ }^{[89]}$ (Fig. 3(c)). This accumulation of a protective microbiome may occur within a few plant generations (also referred to as specific suppressiveness) as illustrated by the take-all decline in wheat ${ }^{[30,90]}$. In contrast, in the case of Fusarium wilt of strawberry, several plant generations are needed for the accumulation of an antagonistic microbiome that can efficiently prevent further reinfections ${ }^{[91]}$. Moreover, in addition to bacteria, other beneficial microbes such as phages, protists or nematodes may also be responsible for the active elimination of pathogens. Crucially, if these consumers can persist in the soil microbial reservoir for a prolonged time, they may provide immunological memory (referred to as soil immune response, Fig. 3(d)) to suppress re-infecting pathogens during current and future plant generations ${ }^{[37,55,92]}$. 
(a) Resistant plants

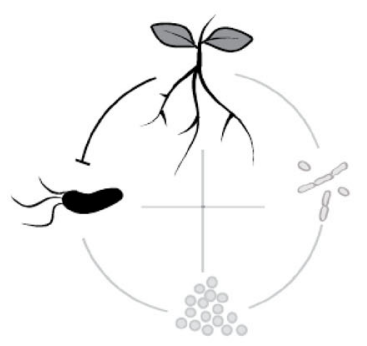

Plant defenses directly suppress pathogens (b) Suppressive soil

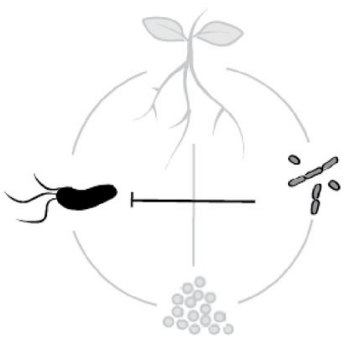

Microbiome constitutively inhibits pathogens (c) Cry for help

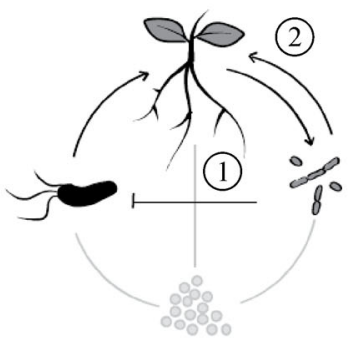

Plant-selected microorganisms (1) Inhibit pathogens

(2) Stimulate plant defenses (d) Soil immunity

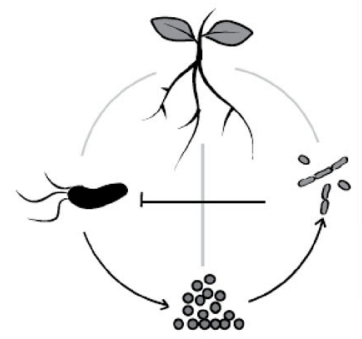

Pathogen-mediated soil alterations foster antagonistic microorganisms

Fig. 3 Rhizosphere immunity can combine several reported mechanisms underlying plant resistance into a whole system approach. (a) Breeding or engineering pathogen resistance into the plant genome can give plants the ability to directly suppress or defend against pathogens; (b) soil suppressiveness, the natural ability of soils to constrain pathogen growth and prevent disease onset, has been consistently linked to direct inhibition of pathogens by soil-dwelling microorganisms; (c) in the "cry for help" hypothesis, plants respond to the presence of a pathogen by actively recruiting microorganisms that directly inhibit pathogens or have positive effects on the activation of plant innate immunity; (d) in the soil immunity hypothesis, pathogen presence triggers changes in the soil structure that can shift the composition of the microbiome toward a more suppressive configuration.

\subsection{Multicomponent immunity}

A major strength of rhizosphere immunity is that it allows combining different components of disease resistance under one unifying concept of immunity. One excellent example of the interactive effects and feedbacks between multiple components is the interplay between soil abiotic properties, plant growth and microbiome recruitment. Soil physico-chemical properties can impose selection on the microbiome, potentially affecting its ability to suppress pathogens by changing microbial gene expression or community composition. Soil properties can also directly affect plant growth, which can further cause feedback loops on microbial community composition and functioning including the growth and abundance of the pathogen. As a result, changing one component may have cascading effects on the other two and vice versa. Predicting and manipulating plant health thus requires a specific understanding of each component and the interactions between them.

\section{Rhizosphere immunity as a theoretical framework for integrative plant disease management}

Rhizosphere immunity may potentially offer an interdisciplinary framework to understand and manage plant health using an integrated and interdisciplinary approach combining plant biology, microbiology and soil sciences. Instead of making the study of each individual component redundant, the main aim of the rhizosphere immunity is to better understand the interactions and interdependencies between them viewing agricultural systems as ecological communities. Below we discuss potential practices that fall within the presented framework and describe how rhizosphere immunity may help in developing integrated pathogen management strategies (Fig. 4).

\subsection{Pathogen-centered management}

Pesticides are widely used to control pathogens to which plants do not have resistance. While pesticides are generally effective in suppressing pathogens in the shortterm they can select for resistant pathogens, potentially leading to a downward spiral of increasing pesticide doses and even more severe disease outbreaks. Crucially, pesticides are often not pathogen-specific, causing substantial collateral damage to commensal and beneficial soil microbiota $^{[93]}$ linked with declining nutrient cycling ${ }^{[94]}$ and removal of toxic compounds ${ }^{[95]}$. These microbiome effects may also indirectly alter plant immunity, direct pathogen suppression by the microbiota and rhizosphere homeostasis. Considering the key importance of the rhizosphere in plant health, it is crucial to develop a new generation of agrochemicals that specifically target pathogens or stimulate specific plant immune responses (e.g., activation of jasmonic acid signaling ${ }^{[45,87]}$ ). Alternative non-pesticide control agents such as highly specific bacteriophages should also be considered ${ }^{[96]}$ as a precision tool to control pathogens without causing negative side effects on the surrounding plant microbiome. 


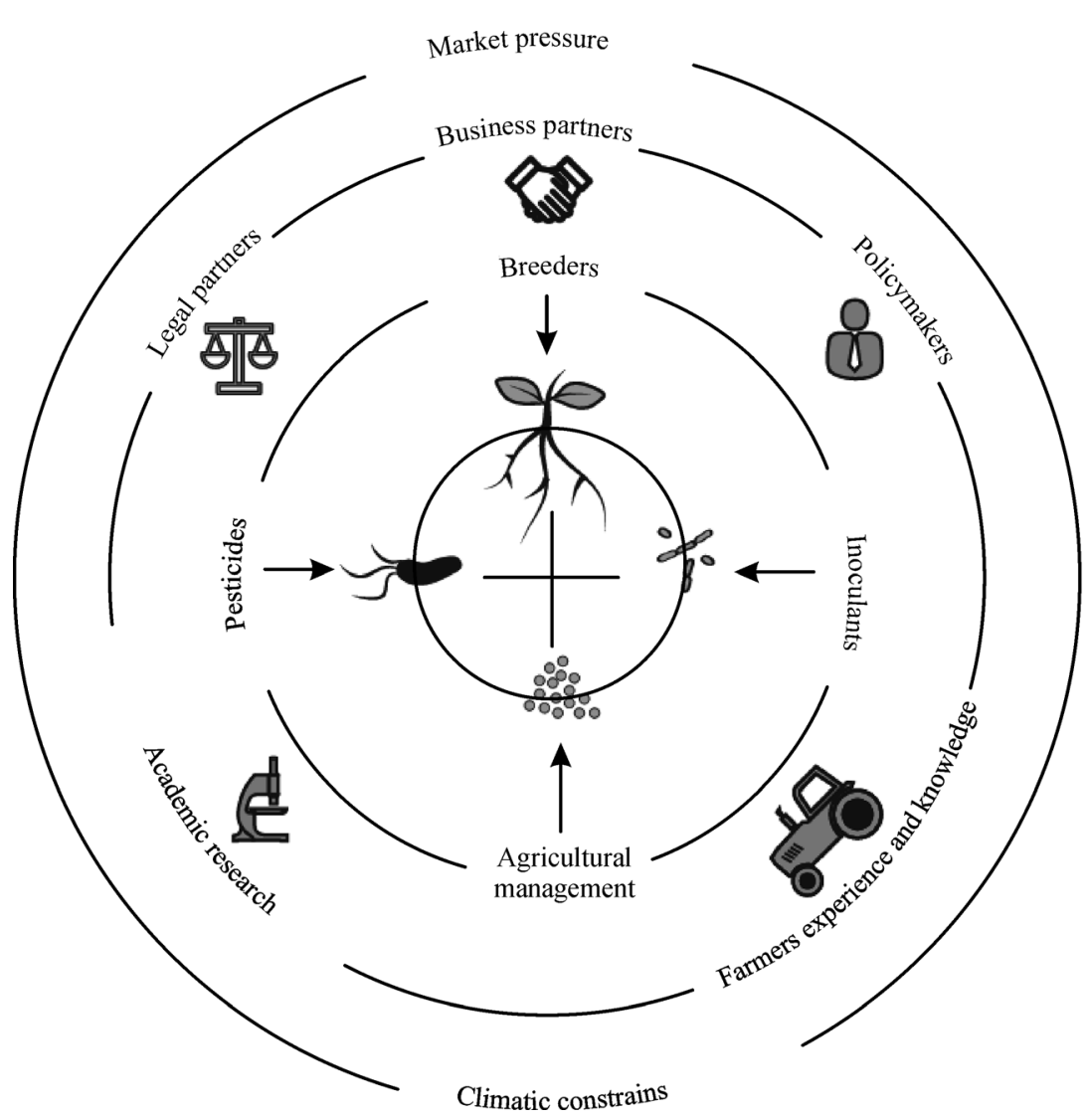

Fig. 4 Integration of rhizosphere immunity in plant disease management. In addition to researchers and scientists, it is important to bring together industrial stakeholders, end-users, legal partners and policymakers. Efficient exchange of knowledge and new multidisciplinary collaborations may be achieved through interdisciplinary conferences, workshops and funding calls and development of common terminology and language. Issues related to intellectual property and legal framework also need to be considered to better understand the practical limitations from the academic, industrial and end-user perspective at local and global levels.

\subsection{Microbiome-centered management}

Application of probiotic microbes as inoculants may enhance pathogen suppression ${ }^{[33,36]}$. One long-standing problem with microbial inoculants is the mismatch between in vitro and in vitro efficacy and relatively low establishment rates in field conditions due to varied microclimatic conditions, physicochemical soil properties and native locally adapted microbial populations. One way to improve this would be to better match the inoculated microbes with the prevailing environmental conditions they will experience at the site of inoculation. Alternatively, instead of introducing new bacteria into the soil, bacteriophages could be used to selectively remove pathogens (or other positively associated bacterial taxa) from the soil ${ }^{[75]}$. For example, it has been shown that bacteriophages can be used in combination with antibioticproducing bacteria ${ }^{[75]}$ or with each other to increase the efficacy of pathogen suppression ${ }^{[96]}$. Moreover, instead of focusing solely on density dynamics of the pathogen, bacteriophages have been shown to drive rapid pathogen evolution where the increased level of bacteriophage resistance is traded off with virulence and high growth resulting in weakened pathogen populations ${ }^{[96]}$.

\subsection{Plant-centered management}

Breeding plants with increased disease resistance has played an important role in improved plant pathogen control. However, breeding plants is a slow and expensive process and is further complicated by difficulties in identifying the right set of genes that, often in combination, are responsible for the resistance. Moreover, expression of resistance mechanisms usually comes with a cost of reduced plant growth ${ }^{[24]}$. While genetic engineering is a highly efficient and environmentally friendly technology, especially when the resistance genes derived from the wild relatives are stacked and recombined in the domestic cultivars $^{[97]}$, the broader use of genetically modified (GM) plants is still held back by regulatory restrictions. Instead of focusing on resistance genes, a new promising approach is to breed plants to promote the growth of specific microbes as differences in microbiome composition between cultivars can explain a large part of their 
sensitivity to pathogens ${ }^{[98-101]}$. Such an approach might restore the natural ability of plants to recruit beneficial microbes, which could have got lost during the development of modern cultivars.

\subsection{Soil-centered management}

Amendment of the soil with organic matter, bioorganic fertilizer, green manure or lime to adjust $\mathrm{pH}$ can improve plant immunity and microbiome suppressiveness ${ }^{[83,102-104]}$. However, the processes through which the incorporated amendments result in reduced disease incidence remain largely unknown, reducing the predictability and repeatability of the process. Smart soil management combining prebiotics with beneficial microbial inoculants may unlock new benefits by concurrently shifting the soil nutritional balance in combination with microbiome functioning ${ }^{[105]}$. We thus propose that soil management should be a key component of all integrated management approaches.

\section{Conclusions}

New integrated and sustainable pest management strategies are of utmost importance in the context of rapidly evolving pathogens, global warming and the demand for low-input agricultural systems (Fig. 4). While considerable effort has been made to develop environmentally friendly ways to control plant diseases such as biological pesticides, resistant plant cultivars, soil amendment practices and microbial inoculants, these management strategies are still mostly applied in isolation. As a result we lack a holistic framework in which multiple management approaches are employed simultaneously to improve plant health. In this perspective we propose rhizosphere immunity as a potential framework for understanding and manipulating complex plant-soil agrisystems using community and ecosystem approach. The key tenet of our approach is that in order to predict and manage plant health it is important to understand not only each component of rhizosphere immunity in isolation, but crucially, also how these components interact and are affected by each other. More research is required to better understand the relative importance of different components of rhizosphere immunity and how they can be ranked and measured objectively using standardized methods. To achieve these goals it is vital to bring together industrial stakeholders, end-users and researchers working in different scientific subdisciplines to allow efficient exchange of knowledge and to foster multidisciplinary collaboration. While such interactions can be promoted via conferences and joint funding schemes, effort is also needed to find a common language and terminology that allow efficient communication between interacting parties. Moreover, issues related to intellectual property and legal framework need to be considered to better recognize the practical limitations from the academic, industrial and end-user perspective at both local and global levels. In practice, integrated pathogen disease management strategies might include a combination of new resistant plant cultivars (via breeding or GM), more defined organic amendments that can selectively change the nutrient balance of the soil, narrowrange pesticides and herbicides with low collateral damage to surrounding ecosystems and high precision, and multifunctional microbial inoculants that can be engineered to match the local environmental conditions at the site of inoculation.

Acknowledgements This research was financially supported by the National Natural Science Foundation of China (41922053, 41671248; ZW), the Fundamental Research Funds for the Central Universities KYXK202009-KYXK202012, the National Key Research and Development Program of China (2018YFD1000800; ZW), and the National Key Basic Research Program of China (2015CB150503; QS). AJ is supported by the Netherlands Organization for Scientific Research project ALW.870.15.050 and the H2020 project "Viroplant". VPF is supported by Royal Society

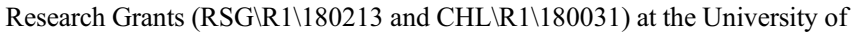
York.

Compliance with ethics guidelines Zhong Wei, Ville-Petri Friman, Thomas Pommier, Stefan Geisen, Alexandre Jousset, and Qirong Shen declare that they have no conflicts of interest or financial conflicts to disclose.

This article does not contain any studies with human or animal subjects performed by any of the authors.

\section{References}

1. Savary S, Willocquet L, Pethybridge S J, Esker P, McRoberts N, Nelson A. The global burden of pathogens and pests on major food crops. Nature Ecology \& Evolution, 2019, 3(3): 430-439

2. Göhre V, Robatzek S. Breaking the barriers: microbial effector molecules subvert plant immunity. Annual Review of Phytopathology, 2008, 46(1): 189-215

3. War A R, Paulraj M G, Ahmad T, Buhroo A A, Hussain B, Ignacimuthu S, Sharma H C. Mechanisms of plant defense against insect herbivores. Plant Signaling \& Behavior, 2012, 7(10): 13061320

4. Kumar H, Kawai T, Akira S. Pathogen recognition by the innate immune system. International Reviews of Immunology, 2011, 30 (1): 16-34

5. Sharrock J, Sun J C. Innate immunological memory: from plants to animals. Current Opinion in Immunology, 2020, 62: 69-78

6. Dong O X, Ronald P C. Genetic engineering for disease resistance in plants: recent progress and future perspectives. Plant Physiology, 2019, 180(1): 26-38

7. Raman R. The impact of Genetically Modified (GM) crops in modern agriculture: a review. GM Crops and Food: Biotechnology in Agriculture and the Food Chain, 2017, 8(4): 195-208

8. Hawkins N J, Bass C, Dixon A, Neve P. The evolutionary origins of pesticide resistance. Biological Reviews of the Cambridge 
Philosophical Society, 2018, 94(1): 135-155

9. Zhang W, Cao G, Li X, Zhang H, Wang C, Liu Q, Chen X, Cui Z, Shen J, Jiang R, Mi G, Miao Y, Zhang F, Dou Z. Closing yield gaps in China by empowering smallholder farmers. Nature, 2016, 537(7622): 671-674

10. Chen X P, Cui Z L, Vitousek P M, Cassman K G, Matson P A, Bai J S, Meng Q F, Hou P, Yue S C, Rmheld V, Zhang F S. Integrated soil-crop system management for food security. Proceedings of the National Academy of Sciences of the United States of America, 2011, 108(16): 6399-6404

11. Teixeira P J P, Colaianni N R, Fitzpatrick C R, Dangl J L. Beyond pathogens: microbiota interactions with the plant immune system. Current Opinion in Microbiology, 2019, 49: 7-17

12. Sánchez-Cañizares C, Jorrín B, Poole P S, Tkacz A. Understanding the holobiont: the interdependence of plants and their microbiome. Current Opinion in Microbiology, 2017, 38: 188-196

13. McNear J, David H. The rhizosphere - roots, soil and everything in between. Nature Education Knowledge, 2013, 4(3): 1

14. Hartmann A, Rothballer M, Schmid M. Lorenz Hiltner, a pioneer in rhizosphere microbial ecology and soil bacteriology research. Plant and Soil, 2008, 312(1-2): 7-14

15. Jones D L, Hinsinger $P$. The rhizosphere: complex by design. Plant and Soil, 2008, 312(1-2): 1-6

16. Brink S C. Unlocking the secrets of the rhizosphere. Trends in Plant Science, 2016, 21(3): 169-170

17. Neutra M R, Kozlowski P A. Mucosal vaccines: the promise and the challenge. Nature Reviews: Immunology, 2006, 6(2): 148-158

18. Jones J D G, Dangl J L. The plant immune system. Nature, 2006, 444(7117): 323-329

19. Dangl J L, Jones J D G. Plant pathogens and integrated defence responses to infection. Nature, 2001, 411(6839): 826-833

20. Chisholm S T, Coaker G, Day B, Staskawicz B J. Host-microbe interactions: shaping the evolution of the plant immune response. Cell, 2006, 124(4): 803-814

21. Bittel P, Robatzek S. Microbe-associated molecular patterns (MAMPs) probe plant immunity. Current Opinion in Plant Biology, 2007, 10(4): 335-341

22. Newman M A, Sundelin T, Nielsen J T, Erbs G. MAMP (microbeassociated molecular pattern) triggered immunity in plants. Frontiers of Plant Science, 2013, 4: 139

23. Carstens M, Katherine J. Plant-pathogen arms race. Science, 2007, 318(5850): 529

24. Anderson J P, Gleason C A, Foley R C, Thrall P H, Burdon J B, Singh K B. Plants versus pathogens: an evolutionary arms race. Functional Plant Biology, 2010, 37(6): 499-512

25. Gururani M A, Venkatesh J, Upadhyaya C P, Nookaraju A, Pandey S K, Park S W. Plant disease resistance genes: current status and future directions. Physiological and Molecular Plant Pathology, 2012, 78: 51-65

26. Ma L J, van der Does H C, Borkovich K A, Coleman J J, Daboussi M J, Pietro A D, Dufresne M, Freitag M, Grabherr M, Henrissat B, Houterman P M, Kang S, Shim W B, Woloshuk C, Xie X H, Xu J R, Antoniw J, Baker S E, Bluhm B H, Breakspear A, Brown D W, Butchko R A EChapman S, Coulson R, Coutinho P M, Danchin E G J, Diener A, Gale L R, Gardiner D M, Goff S, Hammond-Kosack
K E, Hilburn K, Hua-Van A, Jonkers W, Kazan K, Kodira C D, Koehrsen M, Kumar L, Lee Y-H, Li L, Manners J M, MirandaSaavedra D, Mukherjee M, Park G, Park J, Park S Y, Proctor R H, Regev A, Ruiz-Roldan M C, Sain D, Sakthikumar S, Sykes S, Schwartz D C, Turgeon B G, Wapinski I, Yoder O, Young S, Zeng Q D, Zhou S G, Galagan J, Cuomo C A, Kistler H C, Rep M. Comparative genomics reveals mobile pathogenicity chromosomes in Fusarium. Nature, 2010, 464(7287): 367-373

27. Litman G W, Rast J P, Fugmann S D. The origins of vertebrate adaptive immunity. Nature Reviews: Immunology, 2010, 10(8): 543-553

28. Marraffini L A, Sontheimer E J. CRISPR interference: RNAdirected adaptive immunity in bacteria and archaea. Nature Reviews: Genetics, 2010, 11(3): 181-190

29. Danhorn T, Fuqua C. Biofilm formation by plant-associated bacteria. Annual Review of Microbiology, 2007, 61(1): 401-422

30. Berendsen R L, Pieterse C M J, Bakker P A H M. The rhizosphere microbiome and plant health. Trends in Plant Science, 2012, 17(8): 478-486

31. Lozupone C A, Stombaugh J I, Gordon J I, Jansson J K, Knight R. Diversity, stability and resilience of the human gut microbiota. Nature, 2012, 489(7415): 220-230

32. Meade K G, O'Farrelly C. b-Defensins: farming the microbiome for homeostasis and health. Frontiers in Immunology, 2019, 9: 3072

33. Wei Z, Yang T, Friman V P, Xu Y, Shen Q, Jousset A. Trophic network architecture of root-associated bacterial communities determines pathogen invasion and plant health. Nature Communications, 2015, 6(1): 8413

34. Mallon C A, Poly F, Le Roux X, Marring I, van Elsas J D, Salles J F. Resource pulses can alleviate the biodiversity-invasion relationship in soil microbial communities. Ecology, 2015, 96(4): 915-926

35. Mazurier S, Corberand T, Lemanceau P, Raaijmakers J M. Phenazine antibiotics produced by fluorescent pseudomonads contribute to natural soil suppressiveness to Fusarium wilt. ISME Journal, 2009, 3(8): 977-991

36. Hu J, Wei Z, Friman V P, Gu S H, Wang X F, Eisenhauer N, Yang T J, Ma J, Shen Q R, Xu Y C, Jousset A. Probiotic diversity enhances rhizosphere microbiome function and plant disease Suppression. mBio, 2016, 7(6): e01790-16

37. Raaijmakers J M, Mazzola M. Soil immune responses. Science, 2016, 352(6292): 1392-1393

38. Gu Y, Hou Y G, Huang D P, Hao Z X, Wang X F, Wei Z, Jousset A, Tan S Y, Xu D B, Shen Q R, Xu Y C, Friman V P. Application of biochar reduces Ralstonia solanacearum infection via effects on pathogen chemotaxis, swarming motility, and root exudate adsorption. Plant and Soil, 2017, 415(1-2): 269-281

39. Abawi G S, Widmer T L. Impact of soil health management practices on soilborne pathogens, nematodes and root diseases of vegetable crops. Applied Soil Ecology, 2000, 15(1): 37-47

40. Ngeno D C, Murungi L K, Fundi D I, Wekesa V, Haukeland S, Mbaka J. Soil chemical properties influence abundance of nematode trophic groups and Ralstonia solanacearum in high tunnel tomato production. AAS Open Research, 2019, 2: 3

41. Rezanezhad F, Price J S, Quinton W L, Lennartz B, Milojevic T, 
Van Cappellen P. Structure of peat soils and implications for water storage, flow and solute transport: a review update for geochemists. Chemical Geology, 2016, 429: 75-84

42. Narisawa K, Shimura M, Usuki F, Fukuhara S, Hashiba T. Effects of pathogen density, soil moisture, and soil $\mathrm{pH}$ on biological control of clubroot in Chinese cabbage by Heteroconium chaetospira. Plant Disease, 2005, 89(3): 285-290

43. Xun W, Zhao J, Xue C, Zhang G, Ran W, Wang B, Shen Q, Zhang R. Significant alteration of soil bacterial communities and organic carbon decomposition by different long-term fertilization management conditions of extremely low-productivity arable soil in South China. Environmental Microbiology, 2016, 18(6): 1907-1917

44. Venturi V, Keel C. Signaling in the rhizosphere. Trends in Plant Science, 2016, 21(3): 187-198

45. Carvalhais L C, Dennis P G, Badri D V, Kidd B N, Vivanco J M, Schenk P M. Linking jasmonic acid signaling, root exudates, and rhizosphere microbiomes. Molecular Plant-Microbe Interactions, 2015, 28(9): 1049-1058

46. Sasse J, Martinoia E, Northen T. Feed your friends: do plant exudates shape the root microbiome. Trends in Plant Science, 2018, 23(1): 25-41

47. Lebeis S L, Paredes S H, Lundberg D S, Breakfield N, Gehring J, McDonald M, Malfatti S, Glavina del Rio T, Jones C D, Tringe S G, Dangl J L. Salicylic acid modulates colonization of the root microbiome by specific bacterial taxa. Science, 2015, 349(6250): 860-864

48. Downie J A. Calcium signals in plant immunity: a spiky issue. New Phytologist, 2014, 204(4): 733-735

49. Aznar A, Chen N W G, Thomine S, Dellagi A. Immunity to plant pathogens and iron homeostasis. Plant Science, 2015, 240: 90-97

50. Castrillo G, Teixeira P J P L, Paredes S H, Law T F, de Lorenzo L, Feltcher M E, Finkel O M, Breakfield N W, Mieczkowski P, Jones C D, Paz-Ares J, Dangl J L. Root microbiota drive direct integration of phosphate stress and immunity. Nature, 2017, 543 (7646): 513-518

51. Wolf A B, Vos M, de Boer W, Kowalchuk G A. Impact of matric potential and pore size distribution on growth dynamics of filamentous and non-filamentous soil bacteria. PLoS One, 2013, 8(12): e83661

52. Vos M, Wolf A B, Jennings S J, Kowalchuk G A. Micro-scale determinants of bacterial diversity in soil. FEMS Microbiology Reviews, 2013, 37(6): 936-954

53. Serna-Chavez H M, Fierer N, van Bodegom P M. Global drivers and patterns of microbial abundance in soil. Global Ecology and Biogeography, 2013, 22(10): 1162-1172

54. Wei Z, Gu Y A, Friman V P, Kowalchuk G A, Xu Y C, Shen Q R, Jousset A. Initial soil microbiome composition and functioning predetermine future plant health. Science Advances, 2019, 5(9): eaaw0759

55. Bakker P A H M, Pieterse C M J, de Jonge R, Berendsen R L. The soil-borne legacy. Cell, 2018, 172(6): 1178-1180

56. Rashid M I, Mujawar L H, Shahzad T, Almeelbi T, Ismail I M I, Oves M. Bacteria and fungi can contribute to nutrients bioavailability and aggregate formation in degraded soils. Microbiological Research, 2016, 183: 26-41
57. Mazor G, Kidron G J, Vonshak A, Abeliovich A. The role of cyanobacterial exopolysaccharides in structuring desert microbial crusts. FEMS Microbiology Ecology, 1996, 21(2): 121-130

58. Loper J E, Henkels M D. Utilization of heterologous siderophores enhances levels of iron available to Pseudomonas putida in the rhizosphere. Applied and Environmental Microbiology, 1999, 65 (12): 5357-5363

59. Chovatiya R, Medzhitov R. Stress, inflammation, and defense of homeostasis. Molecular Cell, 2014, 54(2): 281-288

60. Lee M H, Jeon H S, Kim S H, Chung J H, Roppolo D, Lee H J, Cho H J, Tobimatsu Y, Ralph J, Park O K. Lignin-based barrier restricts pathogens to the infection site and confers resistance in plants. EMBO Journal, 2019, 38(23): e101948

61. Pollard M, Beisson F, Li Y, Ohlrogge J B. Building lipid barriers: biosynthesis of cutin and suberin. Trends in Plant Science, 2008, 13(5): 236-246

62. Hose E, Clarkson D T, Steudle E, Schreiber L, Hartung W. The exodermis: a variable apoplastic barrier. Journal of Experimental Botany, 2001, 52(365): 2245-2264

63. Beauregard P B, Chai Y, Vlamakis H, Losick R, Kolter R. Bacillus subtilis biofilm induction by plant polysaccharides. Proceedings of the National Academy of Sciences of the United States of America, 2013, 110(17): E1621-E1630

64. Choi H W, Klessig D F. DAMPs, MAMPs, and NAMPs in plant innate immunity. BMC Plant Biology, 2016, 16(1): 232

65. De Lorenzo G, Ferrari S, Cervone F, Okun E. Extracellular DAMPs in plants and mammals: immunity, tissue damage and repair. Trends in Immunology, 2018, 39(11): 937-950

66. de Weert S, Kuiper I, Lagendijk E L, Lamers G E M, Lugtenberg B $\mathrm{J}$ J. Role of chemotaxis toward fusaric acid in colonization of hyphae of Fusarium oxysporum f. sp. radicis-lycopersici by Pseudomonas fluorescens WCS365. Molecular Plant-Microbe Interactions, 2004, 17(11): 1185-1191

67. López-Díaz C, Rahjoo V, Sulyok M, Ghionna V, Martín-Vicente A, Capilla J, Di Pietro A, López-Berges M S. Fusaric acid contributes to virulence of Fusarium oxysporum on plant and mammalian hosts. Molecular Plant Pathology, 2018, 19(2): 440453

68. Notz R, Maurhofer M, Dubach H, Haas D, Défago G. Fusaric acidproducing strains of Fusarium oxysporum alter 2,4-diacetylphloroglucinol biosynthetic gene expression in Pseudomonas fluorescens CHA0 in vitro and in the rhizosphere of wheat. Applied and Environmental Microbiology, 2002, 68(5): 2229-2235

69. Chapelle E, Mendes R, Bakker P A H, Raaijmakers J M. Fungal invasion of the rhizosphere microbiome. ISME Journal, 2016, 10 (1): 265-268

70. Fujiwara A, Fujisawa M, Hamasaki R, Kawasaki T, Fujie M, Yamada T. Biocontrol of Ralstonia solanacearum by treatment with lytic bacteriophages. Applied and Environmental Microbiology, 2011, 77(12): 4155-4162

71. Ye X, Li Z, Luo X, Wang W, Li Y, Li R, Zhang B, Qiao Y, Zhou J, Fan J, Wang H, Huang Y, Cao H, Cui Z, Zhang R. A predatory myxobacterium controls cucumber Fusarium wilt by regulating the soil microbial community. Microbiome, 2020, 8(1): 49

72. Xiong W, Song Y, Yang K, Gu Y, Wei Z, Kowalchuk G A, Xu Y, 
Jousset A, Shen Q, Geisen S. Rhizosphere protists are key determinants of plant health. Microbiome, 2020, 8(1): 27

73. Dickman M, Williams B, Li Y, de Figueiredo P, Wolpert T. Reassessing apoptosis in plants. Nature Plants, 2017, 3(10): 773779

74. Voigt C A. Callose-mediated resistance to pathogenic intruders in plant defense-related papillae. Frontiers of Plant Science, 2014, 5 : 168

75. Wang X, Wei Z, Li M, Wang X, Shan A, Mei X, Jousset A, Shen Q, $\mathrm{Xu}$ Y, Friman V P. Parasites and competitors suppress bacterial pathogen synergistically due to evolutionary trade-offs. Evolution, 2017, 71(3): 733-746

76. Bais H P, Weir T L, Perry L G, Gilroy S, Vivanco J M. The role of root exudates in rhizosphere interactions with plants and other organisms. Annual Review of Plant Biology, 2006, 57(1): 233-266

77. Ji C, Fan Y, Zhao L. Review on biological degradation of mycotoxins. Animal Nutrition, 2016, 2(3): 127-133

78. Radl V, Winkler J B, Kublik S, Yang L H, Winkelmann T, Vestergaard G, Schröder P, Schloter M. Reduced microbial potential for the degradation of phenolic compounds in the rhizosphere of apple plantlets grown in soils affected by replant disease. Environmental Microbiology, 2019, 14(1): 9

79. Komy Z R, Shaker A M, Heggy S E M, El-Sayed M E A. Kinetic study for copper adsorption onto soil minerals in the absence and presence of humic acid. Chemosphere, 2014, 99: 117-124

80. Ye S J, Zeng G M, Wu H P, Zhang C, Liang J, Dai J, Liu Z F, Xiong W P, Wan J, Xu P, Cheng M. Co-occurrence and interactions of pollutants, and their impacts on soil remediation- $-\mathrm{a}$ review. Critical Reviews in Environmental Science and Technology, 2017, 47(16): 1528-1553

81. Weller D M, Raaijmakers J M, Gardener B B M, Thomashow L S. Microbial populations responsible for specific soil suppressiveness to plant pathogens. Annual Review of Phytopathology, 2002, 40(1): 309-348

82. Ren L X, Su S M, Yang X M, Xu Y C, Huang Q W, Shen Q R. Intercropping with aerobic rice suppressed Fusarium wilt in watermelon. Soil Biology \& Biochemistry, 2008, 40(3): 834-844

83. Bonanomi G, Lorito M, Vinale F, Woo S L. Organic amendments, beneficial microbes, and soil microbiota: toward a unified framework for disease suppression. Annual Review of Phytopathology, 2018, 56(1): 1-20

84. Garbeva P, van Veen J A, van Elsas J D. Microbial diversity in soil: selection microbial populations by plant and soil type and implications for disease suppressiveness. Annual Review of Phytopathology, 2004, 42(1): 243-270

85. Conrath U. Systemic acquired resistance. Plant Signaling \& Behavior, 2006, 1(4): 179-184

86. Pieterse C M J, Zamioudis C, Berendsen R L, Weller D M, Van Wees S C M, Bakker P A H M. Induced systemic resistance by beneficial microbes. Annual Review of Phytopathology, 2014, 52 (1): $347-375$

87. Van der Ent S, Van Wees S C M, Pieterse C M J. Jasmonate signaling in plant interactions with resistance-inducing beneficial microbes. Phytochemistry, 2009, 70(13-14): 1581-1588

88. Yuan J, Zhao J, Wen T, Zhao M, Li R, Goossens P, Huang Q, Bai Y, Vivanco J M, Kowalchuk G A, Berendsen R L, Shen Q. Root exudates drive the soil-borne legacy of aboveground pathogen infection. Microbiome, 2018, 6(1): 156

89. Berendsen R L, Vismans G, Yu K, Song Y, de Jonge R, Burgman W P, Burmølle M, Herschend J, Bakker P A H M, Pieterse C M J. Disease-induced assemblage of a plant-beneficial bacterial consortium. ISME Journal, 2018, 12(6): 1496-1507

90. Sanguin H, Sarniguet A, Gazengel K, Moënne-Loccoz Y, Grundmann G L. Rhizosphere bacterial communities associated with disease suppressiveness stages of take-all decline in wheat monoculture. New Phytologist, 2009, 184(3): 694-707

91. Cha J Y, Han S, Hong H J, Cho H, Kim D, Kwon Y, Kwon S K, Crüsemann M, Bok Lee Y, Kim J F, Giaever G, Nislow C, Moore B S, Thomashow L S, Weller D M, Kwak Y S. Microbial and biochemical basis of a Fusarium wilt-suppressive soil. ISME Journal, 2016, 10(1): 119-129

92. Lapsansky E R, Milroy A M, Andales M J, Vivanco J M. Soil memory as a potential mechanism for encouraging sustainable plant health and productivity. Current Opinion in Biotechnology, 2016, 38: 137-142

93. Hartmann M, Frey B, Mayer J, Mäder P, Widmer F. Distinct soil microbial diversity under long-term organic and conventional farming. ISME Journal, 2015, 9(5): 1177-1194

94. Jiao S, Chen W, Wang J, Du N, Li Q, Wei G. Soil microbiomes with distinct assemblies through vertical soil profiles drive the cycling of multiple nutrients in reforested ecosystems. Microbiome, 2018, 6(1): 146

95. Teng Y, Chen W. Soil microbiomes: a promising strategy for contaminated soil remediation: a review. Pedosphere, 2019, 29(3): 283-297

96. Wang X, Wei Z, Yang K, Wang J, Jousset A, Xu Y, Shen Q, Friman V P. Phage combination therapies for bacterial wilt disease in tomato. Nature Biotechnology, 2019, 37(12): 1513-1520

97. Witek K, Jupe F, Witek A I, Baker D, Clark M D, Jones J D G. Accelerated cloning of a potato late blight-resistance gene using RenSeq and SMRT sequencing. Nature Biotechnology, 2016, 34 (6): 656-660

98. Kwak M J, Kong H G, Choi K, Kwon S K, Song J Y, Lee J, Lee P A, Choi S Y, Seo M, Lee H J, Jung E J, Park H, Roy N, Kim H, Lee M M, Rubin E M, Lee S W, Kim J F. Author Correction: rhizosphere microbiome structure alters to enable wilt resistance in tomato. Nature Biotechnology, 2018, 36(11): 1117

99. Wei Z, Jousset A. Plant breeding goes microbial. Trends in Plant Science, 2017, 22(7): 555-558

100. Mendes L W, Raaijmakers J M, de Hollander M, Mendes R, Tsai S $\mathrm{M}$. Influence of resistance breeding in common bean on rhizosphere microbiome composition and function. ISME Journal, 2018, 12(1): 212-224

101. Mendes L W, Mendes R, Raaijmakers J M, Tsai S M. Breeding for soil-borne pathogen resistance impacts active rhizosphere microbiome of common bean. ISME Journal, 2018, 12(12): 3038-3042

102. Xue C, Shen Z Z, Hao Y W, Yu S T, Li Y C, Huang W J, Chong Y, Ran W, Li R, Shen Q R. Fumigation coupled with bio-organic fertilizer for the suppression of watermelon Fusarium wilt disease re-shapes the soil microbiome. Applied Soil Ecology, 2019, 140: 49-56

103. Larkin R P, Griffin T S. Control of soilborne potato diseases using 
Brassica green manures. Crop Protection, 2007, 26(7): 1067-1077

104. Shen G, Zhang S, Liu X, Jiang Q, Ding W. Soil acidification amendments change the rhizosphere bacterial community of tobacco in a bacterial wilt affected field. Applied Microbiology and Biotechnology, 2018, 102(22): 9781-9791
105. Adam E, Groenenboom A E, Kurm V, Rajewska M, Schmidt R, Tyc O, Weidner S, Berg G, de Boer W, Falcão Salles J. Controlling the microbiome: microhabitat adjustments for successful biocontrol strategies in soil and human gut. Frontiers in Microbiology, 2016, 7: 1079 